\title{
Approaches to Statistical Measurement of Advanced Technologies: a Comparative Study.
}

Link to publication record in Manchester Research Explorer

\section{Citation for published version (APA):}

Kadyrova, A. (2015). Approaches to Statistical Measurement of Advanced Technologies: a Comparative Study. (Science, Technology and Innovation).

\section{Citing this paper}

Please note that where the full-text provided on Manchester Research Explorer is the Author Accepted Manuscript or Proof version this may differ from the final Published version. If citing, it is advised that you check and use the publisher's definitive version.

\section{General rights}

Copyright and moral rights for the publications made accessible in the Research Explorer are retained by the authors and/or other copyright owners and it is a condition of accessing publications that users recognise and abide by the legal requirements associated with these rights.

\section{Takedown policy}

If you believe that this document breaches copyright please refer to the University of Manchester's Takedown Procedures [http://man.ac.uk/04Y6Bo] or contact uml.scholarlycommunications@manchester.ac.uk providing relevant details, so we can investigate your claim.

\section{OPEN ACCESS}




\section{NATIONAL RESEARCH UNIVERSITY HIGHER SCHOOL OF ECONOMICS}

Alina R. Kadyrova

\section{APPROACHES TO STATISTICAL MEASUREMENT OF ADVANCED TECHNOLOGIES: A COMPARATIVE STUDY}

BASIC RESEARCH PROGRAM

WORKING PAPERS

SERIES: SCIENCE, TECHNOLOGY AND INNOVATION

WP BRP 38/STI/2015 
Alina R. Kadyroval

\section{APPROACHES TO STATISTICAL MEASUREMENT OF ADVANCED TECHNOLOGIES: A COMPARATIVE STUDY}

The paper presents an analysis of advanced technology classifications development. Despite the variety of technology types - advanced, emerging, disruptive, enabling, best available - the focus of the study is made on the first type considering their precedent character, crucial role for manufacturing and overall economic development.

Various approaches to define the term 'advanced technology' as well as gradual evolution of the definitions and classifications are demonstrated in the paper. It is argued that the initial understanding of advanced technologies was formed in early 1990s and characterized increase in efficiency, hardware and software usage, robotics, etc. Further rapid progress of science and technology in 1990-2010s led to the expansion of the concept by the means of technologies based on fast computing, primarily used for design, control and track of manufacturing activities as well as micro- and nanotechnologies. Moreover, indicators used for measurement of their development and use are compared.

JEL Classification: O14, O31, O33

Keywords: advanced technology, technological development, technology classification

\footnotetext{
${ }^{1}$ National Research University Higher School of Economics, Institute for Statistical Studies and Economics of Knowledge, Research Assistant
} 


\section{Introduction}

Technology development is one of the indicators of economic growth that shows country's competitiveness at international market. Technological progress is considered to be a priority by many countries and national governments, therefore at present time the field is experiencing huge financial investments with the expectations of considerable long- and short-term returns. Additionally, as the Frascati Manual suggests, assessment of technology development allows investors and governments to compare companies in terms of profitability, expediency of investments, market potentials, industry or the whole economy growth (OECD, 2002).

High degree of technology development in the country is followed by an interaction of a high number of different agents (business enterprises, higher education institutions, research institutes, and government) that provides outcomes such as new knowledge, technologies and innovations. Moreover, advancements in technology development ensure major consumers' of technologies civil society - understanding and awareness of $\mathrm{STI}^{2}$, as well as willingness to make a contribution to technology development.

New technologies that support economic development in the country come into the world from the innovation systems aiming at knowledge, innovation and technology creation. These systems likewise any system should be controlled not only at institutional level, but also at regional and country (frequently federal) levels enabling governments to develop an appropriate policy for technology and innovations.

The most complicated element among the knowledge-technology-innovation trine in terms of measurement is technology: it incorporates new knowledge and strongly relates to innovation (though technological innovations). Researchers assess technologies in order to monitor its development, current utilization and possible societal effects, as well as compare technological levels of different industries and analyze technology arrival and dissemination through the different sectors of economy (Gokhberg, et al., 2013). The measurement framework will allow not only governments, but also companies, research institutions and other players to contribute to developing technology polices at national or company levels.

However, before starting monitoring and measurement activities, the object of research should be clearly defined. It is important to identify when the technology starts to emerge and becomes relevant to be estimated in terms of any measurable outcomes. At the same time such identification is not an easy task as far as at early stages it is usually impossible to distinguish new technologies

\footnotetext{
${ }^{2}$ STI - Science, Technology and Innovation
} 
because they are usually embedding in current technologies, not included as single items in organization accounts and, therefore, are not reported in surveys (Gokhberg, et al., 2013). Therefore, a set of questions on the nature of technologies, the boundaries of the concept, methods of identification and assessment of technology implementation results arises. Moreover, practice reveals various difficulties in assessment of the results and almost total absence of any reliable indicators for assessment of any type of technologies. The latter becomes especially crucial while investigating for instance nanotechnology, biotechnology, advanced materials and other highpromising technologies that are rapidly developing in many countries.

Recently several types of technologies such as emerging, disruptive and advanced technologies have attracted wider public attention due to their potential to improve significantly the way people live, companies operate and industries organized. Among three mentioned types of technologies 'advanced' seems to be the broadest category. However, despite the numerous studies, the question when and under which circumstances a specific technology could be named 'emerging', 'advanced' or 'disruptive' remains open due to absence of the strict rules. Additionally, it is difficult to strongly arrange the types according to importance, strength of effects or any another criteria because they all consider technologies from different perspectives.

Emerging technologies recently have been receiving more attention from academics, government and the society due to their higher (in comparison to advanced technologies) publicity. They are said to radically change the world affecting the economies, financial flows and the way people consume, however, the term is usually misunderstood and not well defined. Emerging technologies are characterized by different kinds of uncertainties, such as of outcomes and social impact, high cost and limitations of availability (Halaweh, 2013).

Recent studies (Shipp, 2012; MIT, 2013; LPP, 2009) revealed almost the same list of emerging technologies. For instance, Shipp (2012) mentioned semiconductors, advanced materials, additive manufacturing and biomanufacturing as emerging. Additionally, nanotechnology, micronano electronics, photonics and advanced manufacturing (ARTEMIS, 2013), mobile technologies and biofuels (Groen\& Walsh, 2013) were regarded as emerging. Emerging technologies are rarely included in industry surveys; they are mostly measured through publication and patents activity, interviews with experts or market analysis.

Another term that considers new technologies and could potentially affect producing and consuming patterns is 'disruptive technology'. 'Disruptive technology' is a more managerial term and, therefore, it is mostly studied and reported by consultancy companies. The term focuses on the market perspective and describes the possibility of change of a situation on the market via introducing a new product that will outperform established products. 
Disruptive technologies typically demonstrate a rapid rate of change in technological capabilities in terms of price and performance relative to alternative approaches and substantial potential for disruptive economic impact and changes in the ways people live and work (Institute, 2013). Technologies that meet these requirements for the time being are mobile Internet, cloud technology, 3D printing, next-generation genomics Internet of things, renewable energy, advanced materials, autonomous and near-autonomous vehicles, advanced robotics and energy storage (Institute, 2013).

The third group of technologies - advanced technologies - is of greatest interest of companies as well as the broadest and at present the most intensively researched type of technologies in comparison to emerging, disruptive and the others. Advance technologies include various technologies from flexible manufacturing, computer-aided design to robotics and automated storage systems; they are widely implemented in many industries and play crucial role for manufacturing enterprises and, consequently, allow a vast area for researches of both practical (considering implementation issues) and theoretical (considering classification of technologies, nature of the concept) aspects.

Thus, the purpose of the present study is, firstly, to analyze the approaches to defining advanced technologies and differences among them and, secondly, to assess the classification of advanced technologies and its development with the course of time.

This paper is structured as follows. After a brief overview of technology measurement within the existing statistical frameworks in the first section, the development of advanced technologies definitions, classifications and possible indicators is presented in the second section. The final section discusses limitations of research and possible ways of further development of the present study.

\section{Technology as an object of measurements}

\section{a. Technology within the framework of statistical measurement}

Technology development comprises the integration of several social and governmental institutions, cooperation between different sectors and actors that raises the overall economic growth. The term 'technology' is frequently used in reviews, official reports and surveys, massmedia and books; however, the range of its definitions varies from the shortest forms to broadest. Study (Autio \& Laamanen, 1995).

The term itself became an object of direct measurements only in the middle of the $20^{\text {th }}$ century with the conceptualizing of statistical practices to measure research and scientific activities. Before 
that time the assessment of technology development was made in reliance of research and development measurement that includes implicit and explicit estimation of technology.

Originally, the research had been measured since 1920s and generally in the United States (Godin, 2006). One of the earliest measurements exercises at national level took place in the US. It was carried out by US National Research Council in 1916, similar activities was later made by US Federal Government. However, these practices used distinctive methodology, were occasional and did not contain the definition of the term 'research'. Companies were allowed to decide what should and should not be included in the reports that causes large bias in responses.

Scinctists that contributed to the development of research measurement were J. Huxley and R.Antony. Huxley outlined four types of research: background, basic, ad hoc and development. Huxley's work (Huxley, 1934) influenced the development of the field in a sense that it showed to people the variety of the 'research' concept and included activities. Since that time the research was going to be measured as a set of different activities with the shift to more theoretical (pure research) work or practice-oriented (applied research and development). R.N. Antony outlined what activities should and should not be included when counting research and development: e.g. pilot plants and design should; market research, legal work, technical services should not (Antony, 1952). Finally, due to more or less similar understanding of the nature of research, most countries by 1960s had definitions of research and its components (Godin, 2009). Existing statistical practices in the measurement of scientific activities was conceptualized in the Frascati Manual, which first edition published was prepared by C.Freeman and published in 1963. Later the OECD published 'Frascati Family' - a set of documents related to various aspects of measurement of science and technology activities: innovations (Oslo Manual, first edition in 1992), human resources (Canberra Manual, first issued in 1995), technology purchases (Technology Balance of Payments, first issued in 1990), and patent regulations (Patent Manual, first issued in 1994). However, despite the variety of aspects measured by the Manuals, none of them does not allow the whole operationalization of the term 'technology' and measures of the technology development.

The first problem concerns the definition of the term 'technology'. Both the Frascati and the Oslo Manuals do not contain definitions as well as clearly defined indicators applicable without additional investigations.

General and early definitions of technology that could be found in early articles of the period when these Manuals were released mention that technology is knowledge. H. Simon, for instance, describes technology as 'knowledge of how to do things, how to accomplish human goals' (Simon, 1973). The article highlights that technology are implemented and commercialized due to decisions of several social institutions: decision of consumers (demand), business decision, and political 
decision. Thus, from the beginning of technology study to the researchers it was realized that not every technology ends up in a particular product or process because of influence of technological paradigm, science and technology policy, governmental decisions and consumer's needs.

The early definitions correctly describe the nature and purpose of technologies; however, usage of these definitions is not sufficient for any analysis or measurement. In 90s technologies were defined as 'knowledge embedded in products and processes, and the knowledge of creating, producing, reproducing, and using these products and processes' (Shenhar, 1996). The study (Autio \& Laamanen, 1995) contains rather detailed definition of the term and mentions that technology 'comprises the ability to recognize technical problems, the ability to develop new concepts and tangible solutions to technical problems, the concepts and tangibles developed to solve technical problems, and the ability to exploit the concepts and tangibles in an effective way'. Moreover, when defining 'technology'. The authors also mention that in the definition of technology, it is also important to identify various external factors affecting technological development.

But, unfortunately, the main Manuals on $R \& D$ and innovations (Oslo, Frascati) did not present any attempts to define technologies. It should be mentioned that the $5^{\text {th }}$ edition of the Frascati Manual (1993) contained the definition of advanced manufacturing technologies - a term closely related to the basic term of technology that was not defined properly.

Technology Balance of Payments (TBP) Manual highlights that the term 'technology' origins from French word 'technologie' and means 'study of techniques, tools, machines'(OECD, 1990). English word 'technologies' imply 'set of actions and decision rules guiding their sequential application ... that will generally lead to a predictable (and sometimes desirable) outcome under certain specified circumstances' (OECD, 1990). TBP mentions that the strictest definition of the term refers technology as 'body of knowledge about certain classes of events and activities' interestingly, that definition does not mention science as integral part of technologies implying possible development without resources to science. However, technologies have the operational and practical nature, i.e. they related to either research or development activities thereby linking them. Dual nature of technologies was also highlighted by G.Dosi in the analysis of technological paradigms that will be considered later.

More precise definition contained in the Productivity Manual. Among the set of Manuals the Productivity Manual stands out due to the presence of more or less concrete technology definition. It mentions that technology is 'the currently known ways of converting resources into outputs desired by the economy', and presented in form of blueprints, scientific results, new organizational techniques, or in new products (OECD, 2001). However, the Productivity Manual gives recommendations only on productivity measures, their types and appropriate usage, but not pays 
enough attention to the definition of 'technology' or giving any examples what should be considered as technology. From the Productivity Manual it follows that the borders of the term 'technology' are determined in practice: technology surveys, papers on technology development and other, at which analysts should look at in order to understand what each organization puts in the concept.

The second problem is related to the measurement of technologies. The absence of the unite system of technologies' measurement, standardized and clear indicators, given the differences in each country's technologies' monitoring system complicate the analysis of technologies' development and cross-country comparisons. In order to see the whole picture researchers should extract information on technologies from R\&D surveys, patent information, purchase-sell operations.

As it was mentioned, historically technologies were measured through $\mathrm{R} \& \mathrm{D}$ and/or innovation activities. The first edition of the Oslo Manual (1992) considered only technological product and process innovations; however, with the advancements in surveys and knowledge it was obvious that product and process manufacturing innovation do not cover the whole nature of the term 'innovations'. The third 2005 edition contains methodology of estimating four types of innovation: product, process, marketing and organizational(OECD, 2005). Moreover, originally the Oslo Manual assumed to be more technologically-oriented as soon as the first edition of Frascati Manual stated: 'supplement to the Oslo Manual dealing with advanced manufacturing technology (AMT) surveys is currently planned'. However, the attention to the technological side of innovations and technologies themselves in the 1992 edition of the Oslo Manual gradually moved to the variety of innovations and issues related to its measurement in the third edition of Manual. In addition, the Oslo Manual does not contain any boundaries of the term 'technology' - as well as the Frascati Manual, the boundaries should be defined by each statistical unit.

The Manual that provides information on the indicators for measuring technologies is the Frascati Manual. The Manual recommends to use the GERD/GDP ratio - Gross Domestic Expenditure on $R \& D$ ratio, a sum of intramural expenditure of $R \& D$ performed on national territory in four main sectors - business enterprise, government enterprise, private non-profit, and higher education - during the particular period (OECD, 2002). While the input is measured through R\&D expenditures and $\mathrm{R} \& \mathrm{D}$ personnel, the output of research and development activities, namely new technologies, turned up not an easy thing to measure. The first 1992 edition of Frascati Manual suggested input-output approach; however, later editions pointed out that 'measures of output have not yet reached the stage of development at which it is possible to advance any proposals for standardization'(OECD, 2002). Despite the fact in the Manual it was suggested that patents, 
licensing and technical know-how could be used as measures of output, the data needs intensive additional analysis for output assessment.

Speaking about indicators, it is worth adding that GERD/GDP indicator allows estimating the intensity of R\&D activities mostly at country and international levels and, unfortunately, it is almost the only indicator that could be collected within international statistical frameworks and standards. However, governments and experts usually need more than one indicator for technologies development' assessment as well as more 'localized' data on technologies. For that purpose various national and regional surveys are conducted.

As mentioned, manuals of the Frascati Family contain various measures of scientific and research activity - outputs (patents, licenses) and impacts (technologies flows, productivity) that are only different aspects of the concept 'technology'. 'Technology' is a complex object that has various dimensions - financial, legal, notional, and others. Likewise geometry the Manuals shows only the projections of the multidimensional term 'technologies' in two- or three-dimensional space of e.g. R\&D spends or features of patent activity, while the whole object stays hidden from eyes of researchers.

Approaches to technology measurement will allow, firstly, effective systematization of the knowledge on technology development, dissemination and use technologies, and, secondly, analysis of technological development of the economy and industries. The debates arise on whether it is possible to construct such an indicator system and measures for estimating their convenience and efficiency. The question of what researchers mean mentioning 'advanced technology' and the development of the understanding of the concept will be considered first.

\section{Comparative analysis of measurement of advanced technologies}

\section{a. General definitions}

Advanced technologies comprise various technologies from flexible manufacturing, computer-aided design to robotics and automated storage systems. The pool of advanced technologies is constantly changing due to fast market development, innovations based on science and industry cooperation and replacement of old technologies by new ones. In comparison to emerging technologies, advanced technologies are currently used in the production process, while emerging are still on the stage of developing or early emerging; there is no acute need and mass demand for the technology. 
There were a lot of attempts to define advanced technologies. However, the most prominent changes both in the development of definition and classification, are introduced by national reports or large studies grounded on quantitative and qualitative analysis.

The development of the concept 'advanced technology' relying on the definitions used in the papers and highlighting the differences and additives will be shortly presented in the next paragraphs (list of full definitions used during the analysis could be found in the Appendix 1).

First of all, it should be highlighted that despite the fact that some works focus solely on advanced technologies in a particular region, or do not provide own definition of the term and follow the lists of technologies proposed in other papers, our primary interest is in the methodology of defining technologies as 'advanced' and differences between the approaches.

Before 1960s there were various reports about advances in particular sectors of economic performance: particularly in food industry, in manufacturing, in nuclear industry, etc. The term 'advanced technologies' started to appear in academic papers since 1960s-1970s and mostly implied technologies that are superior in comparison to existing technologies. For instance, in (Robinson, 1974) the authors regard as advanced a new energy storage technology that allows significantly improve its efficiency (the fraction of stored energy that is recoverable). Research carried in 1966 defines advanced technologies as 'the complex of techniques, including the equipment in use and the organization of operations which presumably accounts for their high productivity' (Solo, 1966, p.91). Research of advanced technologies usage in health care (Scott, 1973) mentions that advanced technologies include automation, mechanization, computer utilization; moreover, the study mentions that these technologies should improve the efficiency of health care. Despite the computer usage provided advancements in the specialists' work, it did not corrected deficiencies of health care delivery; hence, the authors mentioned the need of more customized for medicine sphere technologies, such as automated blood analyzer that significantly facilitates and accelerates the work in laboratories. Therefore, the term 'advanced technologies' proved to be not uniform for all the industries, although that the technologies used are based on the same basis of information technologies.

Since 1980s-1990s the number of papers on advanced technologies and variety of definitions started rapidly growing. Even the earliest definitions of advanced technologies mention its computer technologies basement. Thus, according to (Youssef, 1992) advanced technologies is 'a group of integrated hardware-based and software-based technologies, which if properly implemented, monitored and evaluated, will lead to improving the efficiency and effectiveness of the firm in manufacturing a product or providing a service'. Simultaneously to sophistication of definitions the first classifications of advanced technologies started to appear. 
The $5^{\text {th }}$ edition of the Frascati Manual adopts the ideas of technological measurement within the framework of R\&D statistics and highlights not only the fact of microelectronic base and usage of computer control of the advanced technologies, but also the purpose of its usage, namely design, manufacture or handling of the product(OECD, 1993). In such a manner the first implicit mention of pick and place robots ('handling of the product') in light of advanced technologies' studies appeared. Numerous definitions of 2000s replicated the Frascati Manual definition and mentioned features of advanced technologies as such computer control and automatic nature (Dangayach \& Deshmukh, 2004).

Research (Laurila, 1997) mentions that advanced technologies are considered to be risky, but at the same time they lead to a new level of operation in terms of profit. The authors of the study used relatively simple technique to define advanced technology: advanced technology is a technology superior to another. The author presents a comparative analysis of two techniques in paper production implemented by a Finnish company in different time. One technology was found to use more sophisticated technique and higher technological requirements in comparison to the company's previous experience, therefore it was labeled as 'advanced'.

The definitions based on the comparison of the past and present technologies are valid; however, they are broad and do not include some other important distinguishing features of advanced technologies e.g. increase in efficiency highlighted in 1990s studies (Youssef, 1992) .

In (Boyer, et al., 1997) several functions of advanced technologies were mentioned: control, track, or monitor manufacturing activities, either directly or indirectly. Moreover, technologies that do not directly involve computers but closely associated with other advanced manufacturing technologies were also considered as advanced. For instance, bar codes which provide the raw data for a bar code scanner to read and for the associated computer database to monitor.

With the development of manufacturing industries and science the range of advanced technologies applications widens: thus, study (Sun, 2001) mentions information management, design, engineering and fabrication process. Research (Hribik, 2011) adds decision making to advanced technologies possible applications.

In (Gouvea da Costa \& Pinheiro de Lima, 2007) advanced technologies include 'computerand numerical-based apparatus (software and hardware) designed to accomplish or support manufacturing tasks'. The authors try to consider each word of 'advanced manufacturing technology' separately: thus, the characteristic 'advanced' refers to the fact that those technologies use microelectronic-based technologies and computing; the word 'technology' is generally accepted as hardware and apparatus; and 'manufacturing' includes a series of interrelated activities and 
operations involving design, material selection, planning, quality assurance, and marketing of discrete consumer and durable goods.

Research (Institute, 2010) mentions that advanced technologies are associated with installing advanced robotics and intelligent production systems, high-performance computing for modeling, simulation and analysis. Thus, the higher level of systems included in advanced technologies appear in 2010s papers - specifically, intelligent systems and high-level robots that incorporate strong informational technology base and data mining algorithms'.

High level of employees dealing with advance technologies, created system of researchers, machinists, engineers, financiers, business developers, high level of excellence as well as resourcewise usage feature of technologies were highlighted by Deloitte in joint with New England Council analysis (LPP, 2009).

However, recent papers contain only general words about efficiency increase made by advanced technologies application, and highlight their novelty in comparison to existing technologies (Canada, 2007; Institute, 2010; Svobodova, et al., 2011; Walters, 2006), or mention only the list of technologies (Swamidass\& Winch, 2002).

It is clearly seen that all the definitions has relatively the same understanding of advanced technologies. Moving form more simple to more detailed definitions, first common mentioned feature is that advanced technologies are new, or superior in comparison to existing technologies currently used in the company. The transcendence implies increase in efficiency and performance which is the second feature of advanced technologies; and that is obtained with the help of computers - the third feature of advanced technologies. Moreover, definitions also mention the fourth feature of advanced technologies, namely that they use complex algorithms to modeling, design and controlling, in other words, they are intensively used for different kinds of manufacturing processes.

Despite the diversity of researches on advanced technology, most of them concentrate on the advanced technologies usage. Moreover, papers grounded on the empirical data analysis take in consideration advanced manufacturing technologies, a subgroup of advanced technologies. Advanced manufacturing technologies include all the advanced technologies that are used for the purposes of manufacturing, will be considered in the next paragraph.

\section{b. Advanced manufacturing technologies as the subclass of advanced technologies}

Advanced technologies are of great interest of the researchers, businesses and governments due to its important role for the country's level of high-technological goods production, 
development of the front-line areas of science and, therefore, development of the country on the whole.

Advanced technologies represent the new - more effective - way of accomplishing the producer's goals; therefore, they widely used in manufacturing. As it was mentioned in (Shipp, 2012), with the 'use of advanced technologies advanced manufacturing produces goods that minimizes the use of resources and maintains (or maximizes) the cost or performance, results from substantive advancements over the current state of art in the production of the materials'.

Advanced manufacturing was precisely defined by Paul Fowler: 'advanced manufacturing makes extensive use of computer, high precision, and information technologies integrated with a high performance workforce in a production system capable of furnishing a heterogeneous mix of products in small or large volumes with both the efficiency of mass production and the flexibility of custom manufacturing in order to respond rapidly to customer demands'(Institute, 2010). As it is seen, the definition of advanced manufacturing mentions all the features of advanced technologies, namely the intensive usage of computers, high precision, increase in efficiency. However, it additionally highlights that advanced manufacturing requires the integration of several elements, such as technologies, workforce and production systems.

The same idea of integration of several parts was proposed by the US President's Council of Advisors on Science and Technology (Technology, 2012): 'advanced manufacturing is a family of activities that (a) depend on the use and coordination of information, automation, computation, software, sensing, and networking, and/or (b) make use of cutting edge materials and emerging capabilities enabled by the physical and biological sciences.' Moreover, advanced technologies introduced in the Report (Technology, 2012) were regarded as those that 'enable country's manufacturing competitiveness, both in terms of differentiation and tradability of goods'. Moreover, the definition of advanced manufacturing technologies are usually list-based and include the features of advanced manufacturing mentioned by Paul Fowler.

Consequently, the core concept of advanced manufacturing, according to the Fowler's definition that seems to be the most developed, consists in integration of the following components: advanced technologies (based on information technologies usage), well-educated and trained workforce, sufficient technical equipment (hardware and software) and professional management; interaction of these components may lead to improving in performance and efficiency. The interaction will be done under a condition of the system of education institutes, research laboratories and industry cooperation in order to provide sufficient level of education and advances in technical base. Technologies considered by different authors as advanced, will be considered in the next paragraph. 


\section{c. Evolution of advanced technologies classifications}

Similar to the evolution of definitions of advanced technologies, it is possible to retrace the development of their lists basing upon the various studies. Figure 1 shows that the category had started to develop from the certain 'core' and was supplemented by the other technologies that were appeared accordingly to the science and technology development.

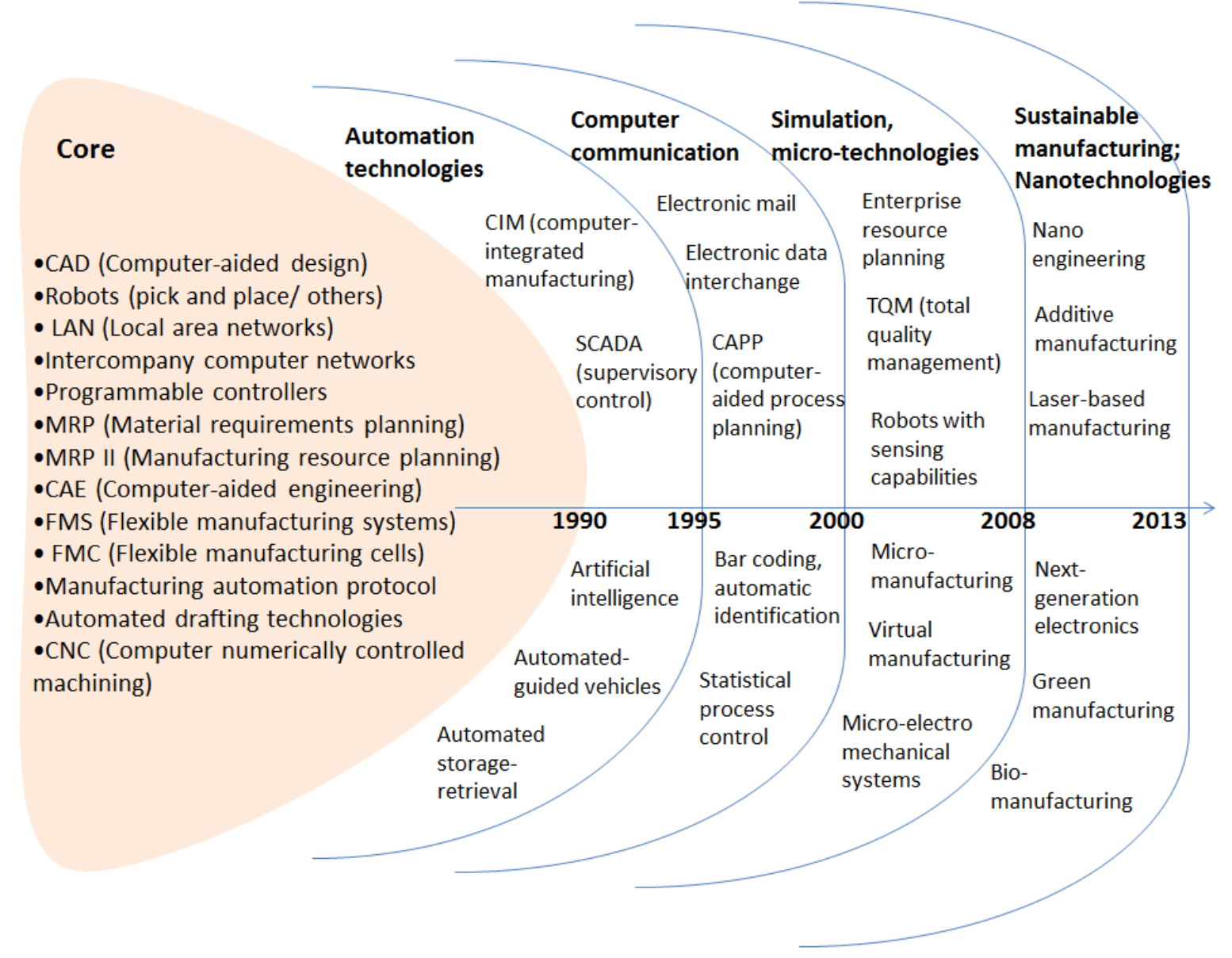

Fig 1. Evolution of advanced technologies classification

As the initial point of the 'core' was considered the list introduced in the earliest found study (Kotha \& Swamidass, 1998) that originates from the US Department of Commerce 1988 (Commerce, 1988). The 'core' of classification includes basic technologies that utilize modeling and planning: computer-aided design (CAD), material requirements planning (MRP), manufacturing resource planning (MRP II) etc. (Figure 1).

The decade 1990-2000s was the 'broadening' stage in the development of advanced technology classifications: during that period the pool of technologies substantially increased. In early 1990s numerous automation technologies for vehicles utilization, handling, storage and retrieval were introduced: computer-integrated manufacturing (CIM), supervisory control and data acquisition (SCADA), automated guided vehicle systems (AGVS), artificial intelligence etc. (Canada, 1993). Late 1990s coincided with the development of Internet and introduced 
standardization and control technologies. Electronic mail and electronic data interchange (Boyer, et al., 1997), shared databases (Sun, 2001) were regarded as advanced technologies and started to be actively utilized for manufacturing and managerial purposes. Importantly, the Internet-generated advanced technologies introduced a block of $\mathrm{ICT}^{3}$ technologies that are crucial for the future development of the whole group of advanced technologies. Moreover, technologies such as computer-aided inspection, testing, tracing (CAITT)(Sun, 2001), statistical process control (SPC)(Pyke, et al., 2002), plant certification (Thakur \& Jain, 2008)) became used in organizations. Importantly, the first step to flexible manufacturing that allows changes in parameters of production according to current needs and demand - just-in-time manufacturing (Pyke, et al., 2002) (later reconfigurable systems (Canada, 2007)) - was proposed also within that period of time.

The beginning of the $21^{\text {st }}$ century introduced various technologies that deal with simulation, modeling (Swamidass \& Winch, 2002), sensors (robots with sensing capabilities) as well as present various advancements in control of production (radio frequency identification, RFID), humanmachine relations and artificial intelligence (human machine interface, HMI, with coordinated motion control) (Canada, 2007). Basically, in comparison to the previous decade that period presents the deepening of the classifications introducing the specification of technologies (i.e. the increase in different sub-types of technology dedicated to various goals), but not the greater number of new ones (in comparison to the previous period).

It should be highlighted that the lists proposed in the latest papers, e.g. (de Weck, et al., 2013) and (Technology, 2012) contain several new for advanced manufacturing groups of technologies. First of all, that is nano-manufacturing, bio-manufacturing, next-generation electronics that by several papers (MIT, 2013) are regarded as emerging technologies due to the fact that these technologies are not widely used by organizations and are more future-oriented. And, secondly, that is 'green' technologies for sustainable manufacturing that formally satisfy the requirements of advanced technologies (increase in efficiency, computer utilization, modeling), but do not ease the work of the employees and probably do not speeds the operations at the plant.

It is important to highlight the authors mention technologies that, doubtless, are related to manufacturing, however, for instance several papers (Pyke, et al., 2002) and (Thakur \& Jain, 2008) mention technologies that do not satisfy the condition of computer utilization: e.g. 'quality circles' a technology that relates more to 'process' advanced technologies, or ISO 9000 - a standard of quality management that satisfies 'increase in effectiveness' and even computer utilization conditions being, however, not a 'technology' itself, but a set of technologies and methods.

${ }^{3} \mathrm{ICT}$ - Information and Communication Technologies 
As it is clearly seen, since the very beginning the 'core' of advanced technologies lists determined the main areas of current and future development, which implies that the concept hasn't considerably changed - from the understanding to the contents - but deepens in technologies variations or broadens due to progress in science and technology. For instance, two types of robots (that can pick and place and others) have stayed the same until 2007 edition of Canada Advanced Manufacturing Survey that introduced robots with sensing capabilities. Moreover, even in 1990s technologies such as artificial intelligence, expert systems were regarded as advanced (Canada, 1993) despite the fact that they became widely used in manufacturing mostly at the beginning of the $21^{\text {st }}$ century.

Academic papers used for the classifications analysis contain lists that vary from the shortest to the broadest. The first reason for the difference consists in the origin of the research.

There are various types of researches on advanced technologies. First of all, there are papers released under the governmental affiliation: cross-country surveys or analytical reports. Survey directly collect information or incorporate block of questions on advanced technologies; they consist of questionnaires, explanatory remarks and most basic definition sufficient for questionnaire filling-in. Analytical reports usually produced by research institutes or statistical offices contain the analysis of current situation in a particular industry or in a country as a whole. The majority of reports contain detailed definitions and classifications since they are grounded on the massive background foundation as well as on recommendations of considerable number of experts and specialists.

Another type of studies is the non-governmental academic papers written by single authors or a group of them that analyze various parameters of advanced technologies similar to the previous group of studies. This group could include analytical reports or surveys as well; however, carried out on the less scale. Academic papers of the second group usually are aimed at more practical questions, rely on empirical data collected by authors' own study or taken from open information sources and therefore propose various indicators of advance technologies implementation such as degree of usage, value added etc. These researches, however, more rarely contain detailed definitions of the term 'advanced technology', they include list-based definitions or use ones from more theoretical grounded reports.

The second reason for the difference in classifications is the assumptions and authors' goals. For instance, Walters analyses small manufacturing firms (Walters, 2006), and therefore uses the list of the most common and relevant advanced technologies shorter than the one used in nationalwide studies such as 1993 Canada Manufacturing Survey (Canada, 1993). Additionally, the lists can vary according to the firm data sets: industries which produce standardized products in high 
volumes would have less need for flexible manufacturing technologies (e.g. flexible manufacturing cells and systems (FMC/FMS) or just-in-time manufacturing), while 'heavy' industries such as mechanical or automobile engineering will intensively use robotics or lasers. However, the majority of technologies in different forms and degree are applicable to all industries.

Classifications presented in governmental or research institutes reports doubtless play a pioneering role being a 'milestones' that indicate the technology development process. These studies are grounded on a basis of deep investigations, empirical data analysis, discussions with experts; in comparison to the other studies they are more fundamental and less subjective. Subjectivity and data set dependency is more common for academic papers and turns out in various research limitations, e.g. resulting from the assumptions or industry choice, while in reports of state parties (or with the participation of them) these limitations tend to small values. However, in terms of the assessment of technology implementation albeit governmental papers describe wider range of indicators, non-governmental present their analysis and practical meaning.

\section{d. Indicators for advanced technology measurement}

The majority of papers that include definitions of 'advanced technology' and lists also contain the indicators for technology usage assessment and often the results of that assessment. The table below presents the range of indicators used by the authors of considered papers.

Tab. 1. Indicators for advanced technologies assessment

\begin{tabular}{|c|c|}
\hline Indicator & Papers \\
\hline \multicolumn{2}{|l|}{ Implementation indicators } \\
\hline $\begin{array}{l}\text { Advanced technologies currently used in the } \\
\text { firm }\end{array}$ & $\begin{array}{l}\text { (Canada, 2007) } \\
\text { (Thakur \& Jain, 2008) } \\
\text { (Dangayach \& Deshmukh, 2004) } \\
\text { (Sun, 2001) } \\
\text { (Svobodová, et al., 2011) } \\
\text { (Sower \& Abshire, 2003) } \\
\text { (Kotha \& Swamidass, 1998) } \\
\text { (Swamidass \& Winch, 2002) }\end{array}$ \\
\hline \multicolumn{2}{|l|}{ Duration of usage } \\
\hline \multicolumn{2}{|l|}{ Distributor's location } \\
\hline Skills required for advanced technology & \\
\hline
\end{tabular}




\begin{tabular}{|c|c|}
\hline implementation & (Canada, 2007) \\
\hline Way of acquisition of technology & \\
\hline $\begin{array}{l}\text { Source of informational assistance during the } \\
\text { adoption of the technology }\end{array}$ & \\
\hline $\begin{array}{l}\text { Degree (high, medium, low) of impact of } \\
\text { advanced technologies' effect of the adoption }\end{array}$ & \\
\hline Intentions to use & (Pyke, 1997) \\
\hline \multicolumn{2}{|l|}{ Financial indicators } \\
\hline Value added & $\begin{array}{l}\text { (Hribik, 2011) } \\
\text { (Sower \& Abshire, 2003) }\end{array}$ \\
\hline $\begin{array}{l}\text { Percent of unit's capital investments in advanced } \\
\text { technologies from } 2005 \text { to } 2007\end{array}$ & $\begin{array}{l}\text { (Canada, 2007) } \\
\text { (Boyer, et al., 1997) }\end{array}$ \\
\hline
\end{tabular}

Indicators used by authors for advanced technologies assessment could be classified into several groups. The first type of indicators is the implementation indicators that measure various aspects of advanced technologies adoption in organization, such as the most frequently and less frequently used technologies, duration of usage, suppliers etc. Basic information given by implementation indicators will allow managers to assess the current technological situation in the organization and see the dynamic changes with the course of time, see the bottlenecks of manufacturing and make decisions about the purchase/elimination of some technologies.

The first three indicators in the table as well as information about the way of acquisition of the technology aim to provide general information about advanced technologies: distribution of suppliers, degree of advanced technologies implementation. That primary information will allow deriving data on situation in country's own advanced technology production via e.g. comparing the rate of own producers of advanced technologies and importers, firm's commitment to advanced technologies usage (adding investment intensity) and recent trends in the development of technologies. Additionally, the way of technologies acquisition will show the situation in patents/licensing sphere in the country in question, the nature of the relations, financial flows among the firms who mostly produce or consume technologies and the rate of firms that effectively produce and implement technologies by their own.

Information about skills required for the technology implementation will allow assessing the degree of change required by advanced technology, including indirect costs associated with the 
advanced technologies such as employees training. In turn, the question on outcomes of technologies will show the results of adopting technologies: productivity, market, organization, product, unit's efficiency change that will show to the firms and to researchers the real of technologies from different perspectives.

While the first type of indicators is the most often used group of indicators, the second group - financial indicators - are used generally less. Financial indicators show the degree of effectiveness of advanced technologies in terms of finance, for instance, value added or incentives for investment in technologies. Moreover, the information on source of informational assistance will reveal the need of firms to attract outside sources of help, firms' ability to manage technologies themselves that all together will show the technological readiness of Canada's firms to implement advanced technologies.

As it is clearly seen from the table, the most common indicators for the technology assessment are in fact the simplest ones in term of data access - technologies currently used in the firm from the first group and value added from the second. While wide range of indicators are usually met in national-wide surveys such as the Canada Manufacturing Survey carried out by official parties, the most studies carried by single researchers use only one (or two) of them due to the potential difficulties in data collection, privacy concern of organizations and rate of response. Moreover, single researchers basically use implementation indicators as soon as even that basic information allows drawing conclusions about technologies usage in a particular region of country. Evidently, studies carried out by state councils, members of state research centers or universities' laboratories contain more detailed classifications of technologies and detailed indicators: they usually have stronger research base, top-level specialists and more responsibility that allows (or forces) them to provide high-quality results of their activities.

Provided by the indicators information will be useful either for state organizations in e.g. launching technological platforms or national programs dedicated to support of firms in developing and implementing technologies, for planning the budget and see the real needs, bottlenecks and problems of industries; or for businesses - in assessment of their own technological base, results of technologies' implementation, and following recent trends in technologies development.

\section{Conclusion and discussions}

Technology is a crucial part of the operation of the majority of industries and, therefore, they are crucial for economies, countries and of our lives. In order to better understand effect of technology implementation, reveal technological trends and manage technology development, technologies should be assessed and monitored. However, as it was shown, the boundaries of 
'technology' concept are vague and not strictly defined that leads to confusion of companies, government and people and difficulties in measurements.

Types of technologies that recently have attracted attention of scientific and civil society are advanced, emerging and disruptive. While emerging and disruptive technologies are relatively 'young' categories as far as they appeared in the academic literature since between the 1990s2000s, advanced technologies have been researched since the 1950s. Therefore, nowadays in terms of importance of played role in the economy advanced technologies are regarded as the main technological group since they have become a basis for the overall manufacturing.

In the present study it was showed that the definitions as well as classifications of advanced technologies have developed step by step with the course of time. Many academic papers contain list-based or simple definitions of advanced technologies, however all the researchers show the same understanding of the concept: advanced technologies are superior to existing ones, they increase the efficiency of work and performance, are based on information technologies, utilize computers with complex algorithms, modeling and design.

Advanced technologies classifications started to developed since the 1990s along with the development of science and technology. The process of classifications development started from the 'core' list - that was found in (Kotha \& Swamidass, 1998) that uses the classification developed by the US Department of Commerce in 1988 (Commerce, 1988). It was showed that even the 'core' list contained the basic manufacturing technologies currently used in industries (such as computeraided design and material requirements planning) that with the time become only highly specialized. In turn, new technologies that appear due to science and technology development (such as sensors, advanced robots, micro manufacturing) were gradually added to classifications when they became widely used for manufacturing purposes.

Regarding emerging and disruptive technologies, it is clearly seen from the literature that the categories are at the initial stages of research since there are lack of studies that contain more or less strict definition of concepts, classification and indicators. Only a few studies describe in details methods of distinguishing chosen technologies from the conventional ones or advanced technologies. Most common methods include analysis of economic data on the particular region, interviews with the experts, market analysis and surveys. Lack of data mining techniques in technology analysis could be explained by the fact that the potential of the technology effects, its development and 'emerging' or 'disruptive' character is be seen mostly by 'insiders' of industries, not by researchers or scientists. Moreover, since these technologies have recently emerged the results of their implementation is not as obvious and simply indicated that of advanced ones. 
However, small inconsistency in results of technology studies occurs: some technologies were regarded as emerging and advanced simultaneously (e.g. bio- and nano-manufacturing, advanced materials as 'advanced' in (Technology, 2012), while as 'emerging' in (MIT, 2013)). The reason for such results is in authors' perceptions of different types of technologies, in time of conducting a research, and, usually, in commonly accepted way of naming a particular type of technology among a group of researchers that the authors belong to.

To conclude, it is clearly seen that all the types of technologies play an important role in the development of economy as well as in life of the society. Therefore, there is a need of research and understanding their potentials, impacts and possible implications for various purposes.

The future focus of the work is more detailed research of literature on emerging and disruptive technologies, developing their classifications and comparative analysis among the three types.

\section{References}

(ISI), F. I. f. S. a. i. R., 2012. European Manufactuirng Survey (EMS), Karslruhe: s.n.

Abernathy, W., 1978. Patterns of industrial innovation. Technology Review.

Anderson, T., 2014. Pipeline advanced technologies. The Journal of Pipeline Engineering.

Antony, R., 1952. Management Controls in Industrial Research Organizations. Boston: Harvard University.

Arslan, M., Seker, S. \& Kizil, C., 2014. Innovation Driven Emerging Technology from two Contrary

Perspectives: A Case Study of Internet. Emerging Markets Journal.

ARTEMIS, 2013. Draft Annual Work Programme 2013 for the ARTEMIS Programs, б.м.: б.н.

Astebro, T., 1995. Theory of technology: A reply for Rias van Wyk. s.l., s.n.

Australian Bureau of Statistics, 1998. Innovation in Manufacturing, Canberra: s.n.

Beaumont, N., Schroder, R. \& Sohal, A., 2002. Do foreign-owned firms manage advanced manufacturing technology better. International Journal of Operations and Production Management, 22(7), pp. 759-771.

Booth, C., Iyer, S. \& Lebegue, F., 2011. Technology trends: deciding which one will matter, s.1.: BCG.

Boyer, K., Leong, G., Ward, P. \& Krajewski, L., 1997. Unlocking the potential of advanced manufacturing technologies. Journal of Operations Management, Volume 15, pp. 331-347.

Canada, S., 1993. Survey of Innovation and Advanced Technology, s.l.: s.n.

Canada, S., 2007. Survey of Advanced Technologies, s.1.: s.n.

Chandler, A., 1977. The Visible Hand: The Managerial Revolution in American Business.. Cambridge:

Belknap Press. 
Commerce, U. D. o., 1988. Manufacturing Technology 1988. A Bureau of Census Report, Washington DC: US Government Printing Office.

Communities, C. o. t. E., 2009. Communication from the commission to the European Parliament, the Council, the European Economic and Social Committee and the Committee of the Regions, Brussels: s.n.

Dangayach, G. \& Deshmukh, S., 2004. Advanced manufacturing technologies: evidences from Indian automobile companies. International Journal of Manufacturing Technology and Management, 6(5).

de Weck, O., Reed, D., Sarma, S. \& Schmidt, M., 2013. Trends in Advanced Manufacturing Technology Innovation. In: Production in the Innovation Economy. s.1.:MIT.

Dosi, G., 1982. Technological paradigms and technological trejectories. A suggested interpretation of the determinants and directions of technical change. Reserach Policy, pp. 147-162.

Elders, J., Spiering, S. \& Walsh, S., 2001. Microsystems Technology (MST) and MEMS Applications: An Overview. MRS Bulletin.

Freeman, C., 1962. Research and development: a comparison between British and American industry.. National Institute Economics Review, Tом 20, pp. 21-39.

Freeman, C., Poignant, R. \& Svennilson, I., 1963. Science, Economic Growth and Government Policy.. Paris: OECD.

Gertler, M., 1995. "Being There": Proximity, Organization, and Culture in the Development and Adoption of Advanced Manufacturing Technologies. Economic Geography, 71(1).

Godin, B., 2003. The Emergence of S\&T Indicators: Why Did Governments Supplement Statistics with Indicators?. Research Policy, 32(4), pp. 679-691.

Godin, B., 2006. Research and Development: how the 'D' got into R\&D. Science and Public Policy, 33(1), pp. 59-76.

Godin, B., 2007. Science, accounting and statistics: The input-output framework. Research Policy, Volume 36, pp. 1338-1403.

Godin, B., 2009. The making of science, technology and innovation policy: conceptual frameworks as narratives. Montreal: Institut national de la recherche scientifique.

Godin, B., 2009. The Rise of Innovation Surveys: Measuring a Fuzzy Concept. s.l., s.n.

Gokhberg, L., Fursov, K., Miles, I. \& Perani, G., 2013. Developing and using indicators of emerging and enabling technologies. In: Handbook of innovation indicators and measurement. Northampton: Edward Elgar.

Gouvea da Costa, S. \& Pinheiro de Lima, E., 2007. Advanced manufacturing technology adoption: an integrated approach. Journal of Manufacturing Technology Management, 20(1).

Granberg, G. \& Stankiewicz, R., 1981. The development of generic technologies - the cognitive aspects.. In: Technological and Industrial Policy in China and Europe.. Lund: Research Policy Institute.

Groen, A. \& Walsh, S., 2013. Introduction to the Field of Emerging Technology Management. INTRODUCTION TO THE FIELD OF EMERGING TECHNOLOGY MANAGEMENT, 22(1). 
Halaweh, M., 2013. Emerging Technology: What is it?. Journal of Technology Management and Innovation, Volume 3.

Hribik, J., 2011. Evaluation of using advanced manufacturing technologies and clusters of advanced technologies.. s.l., s.n.

Huxley, J., 1934. Scientific Research and Social Needs. London: Watts and Co..

Institute, M. G., 2013. Disruptive technologies: Advances that will transform life, business, and the global есопоту. б.м.:б.н.

Institute, S. a. T. P., 2010. White Papers on Advanced Manufacturing Questions. DRAFT Working Papers Version 040510. Washington, DC: s.n.

Janeček, V. \& Hynek, J., 2009. Hodnocení prínosů vyspělých technologií, s.1.: Gaudeamus.

Johnson, H. \& Kaplan, R., 1987. Relevance Lost: The Rise and Fall of Management Accounting.. Boston: harvard Business School Press.

Johnston, R., 1972. The internal structure of technology. In: The Sociological Review Monograph 18. Keele: J.H. Brookers Printers Limited.

Kolachi, N., 2005. A qualitative analysis of emerging E-commerce technologies and their effects on changing business patterns. Hong Kong, s.n.

Kotha, S. \& Swamidass, P., 1998. Advanced manufacturing technology use: exploring the effect of the nationality variable. International Journal of Production Research, 36(11).

Kuhn, T., 1970. The Structure of Scientific Revolutions. s.1.:University of Chicago Press.

Laurila, L., 1997. The thin line between advanced and conventional new technology: a case study on paper industry management. Joumat of Management Studies, 34(2).

Lindberg, P., Voss, S. \& Blackmon, K., 1998. International Manufacturing Manufacturing Strategies: Context, Content and Changes, Kluwer: s.n.

LPP, N. E. C. a. D. C., 2009. Reexamining advanced manufacturing in a networked world. Prospects for a resurgence in New England. s.l.:s.n.

Lundvall, B., 1992. National Innovation Systems: Towards a Theory of Innovation and Interactive Learning. London: Pinter.

Mansfield, E., 1968. The Economics of Technological Change. New York: Norton.

MIT, 2013. 2013 Emerging Trends Report. In: MIT Technology Review. s.l.:s.n.

National Science Foundation, 1953. Washington: Federal Funds for Science.

OECD, 1990. Proposed Standard Method of Compiling and Interpreting the Technology Balance of Payments Data. Paris: s.n.

OECD, 1993. Frascati Manual. Paris: s.n.

OECD, 2001. Measuring productivity: measurement of aggregate and industry-level productivity growth. Paris: s.n. 
OECD, 2002. Frascati Manual. Paris: s.n.

OECD, 2005. Handbook on Economic Globalisation Indicators. Paris: б.н.

OECD, 2005. Oslo Manual. Paris: s.n.

OECD, 2009. Patent Statistics Manual. s.l.:s.n.

Peine, A., 2008. Technological paradigms and complex technical systems - The case of Smart Homew. Research Policy, Volume 37, pp. 508-529.

Pyke, D., 1997. A Note on Operations Strategy. Hanover: The Tuck School of Business.

Pyke, D., Farley, J. \& Robb, D., 2002. Manufacturing Technology and Operations in China: A Survey of State-owned Enterprises, Private Firms, Joint Ventures and Wholly-owned Foreign Subsidaries. European Management Journal, 20(4).

Robinson, A., 1974. Energy Storage (II): Developing Advanced Technologies.

Sabourin, D. \& Beckstead, D., 1998. Technology adoption in Canadian manufacturing: survey of advanced technology in Canadian manufacturing, Ontario: s.n.

Schumpeter, J., 1934. The Theory of Economic Development: An Inquiry into Profits, Capital, Credit, Interest, and the Business Cycle. s.1.:Harvard University Press.

Scott, C., 1973. Health-caredelivery and advanced technology. SCIENCE.

Shenhar, A., 1996. Management of technology boundaries. s.l., s.n.

Shipp, S., 2012. Emerging global trends in advanced manufacturing. б.м.:INSTITUTE FOR DEFENSE ANALYSES.

Simon, H., 1973. Technology andenvironment. Management Science.

Solo, R., 1966. The capacity to assimilate an advanced technology. American Economic Review.

Sower, V. \& Abshire, R., 2003. Successful implementation of advanced manufacturing technology: A cross sectional study. International Journal of Computer Applications in Technology, 16(1).

Sun, H., 2001. Evaluating Advanced Manufacturing Technology in Chinese State-Owned Enterprises: A Survey and Case Studies. The International Journal of Advanced Manufactruing Technology.

Sun, H., Tian, Y. \& Cui, H., 2001. Evaluating Advanced Manufacturing Technology in Chinese StateOwned Enterprises: A Survey and Case Studies. International Journal of Advanced Manufacturing Technology, Том 18, p. 528-536.

Svobodová, L., Hynek, J. \& Janeček, V., 2011. Advanced manufacturing technology: anticipated and realized benefits. s.l., s.n.

Swamidass, P. \& Winch, G., 2002. Exploratory study of the adoption of manufacturing technology innovations in the USA and the UK. International Journal of Production Research, 40(12).

Technology, P. C. o. A. o. S. a., 2012. Report to the President on capturing domestic competitive advantage in advanced manufacturing, s.l.: s.n. 
Thakur, L. \& Jain, V., 2008. Advanced manufacturing techniques and information technology adoption in India: A current perspective and some comparisons. International Journal of Advanced Manufacturing Technoogy, Volume 36, pp. 618-631.

Walters, A., 2006. Case studies on advanced technology implementation in small companies. International Journal of Innovation and Technology Management, 3(2).

Wheelwright, S., 1984. Manufacturing strategy: defining the missing link. Strategic Management Journal, $5(1)$.

Youssef, M., 1992. Getting to know advanced manufacturing technologies. Industrial Enginerering, 24(2).

\section{Appendix}

\section{Definitions of advanced technologies}

1. Advanced technologies is 'a group of integrated hardware-based and software-based technologies, which if properly implemented, monitored and evaluated, will lead to improving the efficiency and effectiveness of the firm in manufacturing a product or providing a service. (Youssef, 1992)

2. Advanced manufacturing technology is defined as computer-controlled or micro-electronics based equipment used in the design, manufacture or handling of a product. Typical applications include computer-aided design (CAD), computer-aided engineering (CAE), flexible machining centers, robots, automated guided vehicles, and automated storage and retrieval systems. These may be linked by communications systems (factory local area networks) into integrated flexible manufacturing systems (FMS) and ultimately into an overall automated factory or computer-integrated manufacturing system (CIM). (OECD, 1993)

3. Advanced technologies are technologies which primarily utilize computers to control, track, or monitor manufacturing activities, either directly or indirectly. (Boyer, et al., 1997)

4. The term AMT is used in this research as an umbrella term to describe a variety of technologies which primarily utilize computers to control, track, or monitor manufacturing activities, either directly or indirectly. (Boyer, et al., 1997)

5. AMT refers to those computer-aided technologies in information management, design, engineering and fabrication processes such as computer-aided manufacturing (CAM), computer-aided design (CAD) and computer-aided process planning (CAPP). AMTs are the main technical components of computer integrated manufacturing (CIM) systems. (Sun, et al., 2001) 
6. AMTs include computer-driven hard technologies such as computer-aided design (CAD), computer-aided engineering (CAE), computer-aided manufacturing (CAM), FMS and computer-aided process planning, etc. (Swamidass \& Winch, 2002)

7. 'Advanced manufacturing technologies' (AMT) is a term that covers a broad spectrum of computer-controlled automated process technologies. (Dangayach \& Deshmukh, 2004)

8. Advanced technologies are based on the information technologies (Walters, 2006).

9. Advanced technologies include computer- and numerical-based apparatus (software and hardware) designed to accomplish or support manufacturing tasks. (Gouvea da Costa \& Pinheiro de Lima, 2007)

10. Advanced technologies are those technologies that allow significant improvements in production over traditional of more commonly technologies. (Canada, 2007)

11. Advanced technologies are associated with the process improvements, installing advanced robotics and intelligent production systems, high-performance computing for modeling, simulation and analysis (Institute, 2010).

12. For advanced manufacturing technology (AMT) can be considered all available production technology currently used in companies that support the operation of the company in terms of production, control, decision making and administration (Hribik, 2011)

13. AMT is commonly known as a term used for description of the new technology in manufacturing which utilizes the power of many new technologies and particularly computers. (Svobodová, et al., 2011)

\section{Contact details and disclaimer:}

Alina R. Kadyrova

National Research University Higher School of Economics (Moscow, Russia). Institute for Statistical Studies and Economics of Knowledge, research assistant; E-mail: akadyrova@hse.ru, Tel. +7 (495) 772-95-90*12113

\section{Any opinions or claims contained in this Working Paper do not necessarily reflect the views of HSE.}

CKadyrova, 2015 